\title{
Desigualdade salarial de gênero e o abismo salarial entre os gêneros
}

\author{
Unequal gender pay and gender pay gap
}

\section{Cinara Nahra}

Docente do departamento de filosofia da UFRN

\section{Fernanda Alves da Costa}

Doutoranda pelo departamento de filosofia da UFRN

Resumo: Neste artigo estaremos discutindo a desigualdade salarial de gênero (unequal gender pay) e o abismo salarial entre os gêneros (gender pay gap) mostrando que embora os dois fenômenos façam parte da mesma lógica, ou seja, a injusta lógica de desvalorização das mulheres e do trabalho feminino, eles são dois fenômenos distintos. A desigualdade salarial de gênero acontece quando homens e mulheres recebem da mesma fonte pagadora salários distintos pelo mesmo trabalho, ou seja, os homens recebem mais para realizar o mesmo trabalho que as mulheres realizam. Já o abismo salarial (pay gap), acontece quando é feita a média dos salários pagos por uma empresa ou organização aos seus trabalhadores e verifica-se que a média salarial dos homens é maior que a média salarial das mulheres. Discutimos aqui porque estas desigualdades acontecem e propomos seis explicações de ordem cultural, moral e psicológica para os fenômenos, a saber, a ganância masculina, o apelo ao "direito natural" do pai de 
família, o falso mito da maior produtividade masculina, o "apelo do pavão", o efeito Matilda e o princípio Fannie Hurst.

Palavras-chave: desigualdade salarial de gênero, abismo salarial, o apelo do pavão, ganância.

Abstract: In this article we will be discussing the unequal gender pay and the gender pay gap showing that even so they are part of the same logic, i.e, the unfair logic of devaluating woman work, they are two different phenomena. The unequal gender pay is when women and men receive from the same payer different salaries, I mean, men receive more than women. The pay gap happens when the average salary of men is much higher than the average salary of women. We discuss here why these inequalities are happening and we propose six possible cultural, moral and psychological explanations for this: male greediness, the appeal to the "natural right" of the head of the family, the false myth of higher male productivity, the "peacock appeal", The Matilda effect and the Fannie Hurst principle.

Keywords: unequal gender pay, gender pay gap, the peacock appeal, greediness.

Como poremos então a questão? E antes de mais nada, quem somos nós para apresentá-la? Os homens são parte e juiz; as mulheres também. Onde encontrar um anjo? Em verdade, um anjo seria mal indicado para falar, ignoraria todos os dados do problema; quanto ao hermafrodita, é um caso demasiado singular, não é homem e mulher ao mesmo tempo, mas antes, nem homem, nem mulher. Creio que para elucidar a situação da mulher são ainda certas mulheres as mais indicadas.

Simone de Beauvoir, O Segundo Sexo.

\footnotetext{
S fenômenos chamados desigualdade salarial de gênero (unequal gender pay), e o abismo salarial entre os gêneros (gender pay gap), acontecem mundialmente, e são mais uma prova das desigualdades e injustiças a que nós mulheres estamos submetidas. Embora os dois fenômenos façam parte da mesma lógica, ou seja, a injusta lógica de desvalorização
} 
das mulheres e do trabalho feminino, eles são dois fenômenos distintos. A desigualdade salarial de gênero acontece quando homens e mulheres recebem da mesma fonte pagadora salários distintos pelo mesmo trabalho, ou seja, os homens recebem mais para realizar o mesmo trabalho que as mulheres realizam. Já o abismo salarial (pay gap), acontece quando é feita a média dos salários pagos por uma empresa ou organização aos seus trabalhadores e verifica-se que a média salarial dos homens é maior que a média salarial das mulheres. Isto acontece, geralmente, porque os cargos mais bem pagos nestas empresas e organizações são ocupados por homens, ou seja, há mais homens em posições de alta direção e poder do que mulheres.

A existência da desigualdade salarial de gênero (unequal gender pay) em alguns países é proibida por lei, mas isto não a torna inexistente. Nos EUA existe desde 1963 o equal pay $a c t$, uma lei que proíbe a discriminação entre os sexos no pagamento de salários. No Reino Unido uma lei similar foi promulgada em 1970 e atualizada em 2010. No Brasil, teoricamente, a igualdade salarial está garantida desde a promulgação da CLT (Consolidação das Leis do Trabalho), em 1943, tendo sido reforçada na constituição de 1988. O fato de que a desigualdade salarial de gênero (unequal gender pay) seja proibido por lei em muitos países leva a pensar que esta desigualdade não existe, mas isto está longe de ser a realidade, já que como uma infinidade de outras leis, esta também não é cumprida.

Aqui no Brasil, segundo o Global Gender Gap Report ${ }^{14}$ existe "uma significante inversão no progresso do país na direção da paridade de gênero em 2018, com a diferença média (overall gender gap), o abismo salarial, no seu maior ponto desde 2011". Quando olhamos mais detalhadamente ao perfil do Brasil no relatório, os dados são ainda mais preocupantes. Em termos de wage equality for similar work (equidade salarial por trabalho

14 The Global Gender Gap Report 2018. http://www3.weforum.org/ docs/WEF_GGGR_2018.pdf World Economic Forum p.23. "O Brasil vê um significante retrocesso em relação ao progresso em direção a paridade de gênero este ano, como o gap médio de gênero estando no seu maior ponto desde 2011." Acesso em: 18 outubro 2019. 
similar) através de uma pesquisa por amostra, o Brasil ocupa a $132^{\mathrm{a}}$ posição no ranking ${ }^{15}$.

Por que estas desigualdades acontecem? Há explicações objetivas para o abismo salarial (gender gap) Ele acontece porque, mesmo com o ingresso das mulheres no mercado de trabalho, os homens sempre ocuparam os postos mais bem remunerados e de mais poder. Assim, ainda que em muitas empresas o número de mulheres empregadas seja maior do que o de homens, os cargos mais bem pagos e de direção pertencem em geral aos homens e com isso, quando se faz a média entre o que ganham as mulheres e o que ganham os homens nestas empresas e organizações obtém-se como resultado que a média salarial é maior no grupo dos homens do que no grupo das mulheres. Elas acontecem porque o mundo do trabalho é reflexo da nossa sociedade, na qual a igualdade de gêneros nunca existiu. Uma das explicações possíveis para isso é que, como sabemos, o trabalho doméstico e o cuidado com os parentes (filhos e pais) é na grande maioria das famílias assumido desigualmente, com uma participação muito maior das mulheres, e isto se reflete no mundo do trabalho, com as mulheres trabalhando assalariadamente menos horas do que os homens, o que refletiria nos seus rendimentos. Isto, no entanto, não é sempre verdadeiro, já que mesmo com a dupla jornada de trabalho muitas mulheres trabalham as mesmas horas que os homens e muitas vezes até mais. O que realmente acontece é que os postos melhor remunerados acabam sendo ocupados pelos homens, mesmo em um país como o Brasil, onde o nível de escolaridade das mulheres já supera o dos homens ${ }^{16}$. As causas do gender gap só podem ser explicadas, me parece, se levarmos em conta fatores objetivos relacionados a própria essência do capitalismo selvagem (savage capitalism). Além do fato objetivo de que as mulheres podem engravidar e necessitar de licença maternidade, o que parece ser o pior dos pesadelos para empregadores, há fatores subjetivos relacionados ao preconceito. O preconceito,

$15 \quad$ Ibid., ver country profile, Brasil, p.41

16 Ver IBGE, censo demográfico disponível em: https://www.ibge.gov. $\mathrm{br} / \mathrm{apps} / \mathrm{snig} / \mathrm{v} 1 /$ ?loc $=0 \& \mathrm{cat}=-1,1,2,-2,3,4,13,48,128$ \&ind $=4699$ Acesso em: 18 outubro 2019. 
como se sabe, é sempre sutil e muitas vezes inconsciente (unconsciuous bias). Os responsáveis por contratações, sejam eles homens ou mulheres, jamais vão admitir que escolherem um homem para uma posição, ao invés de uma mulher, pelo mero fato de que um é homem e a outra é mulher, mas inconscientemente o preconceito pode ter operado durante todo o processo de escolha. A ideia de que os homens podem se dedicar mais ao trabalho por estarem menos ocupados com tarefas familiares é uma ideia que está muitas vezes inconscientemente presente nos responsáveis por contratações, operando em suas decisões.

Já as explicações para a desigualdade salarial de gênero (unequal pay) parecem ser mais complexas, embora a natureza básica do problema seja a mesma, ou seja, fatores relacionados a essência do capitalismo. A existência da desigualdade salarial de gênero, embora esta seja proibida por lei em muitos países, e embora seja um problema histórico, adquiriu visibilidade no início do século XXI, especialmente pela luta incansável de grandes desportistas, como a tenista Serena Williams, a futebolista americana Megan Rapinoe e a brasileira Marta Silva. Serena Williams sempre foi uma grande lutadora pela igualdade salarial (equal pay) e se as mulheres recebem o mesmo pagamento que os homens desde 2007 nos torneios de tênis em Wimbledon, isto é devido em grande parte a sua luta e a de todas as tenistas, sendo que hoje em todos os torneios do Grand slam os campeões e as campeãs recebem o mesmo valor. O mesmo está longe de acontecer no futebol, e a injustiça fica ainda mais clara nos EUA onde a US Soccer Federation paga menos para as mulheres do que para os homens, ainda que a performance da seleção feminina americana seja infinitamente superior à da seleção masculina, o que é comprovado pelos inúmeros torneios onde a seleção feminina americana saiu vitoriosa. A seleção feminina dos EUA conquistou quatro vezes a medalha de ouro em Olimpíadas (1996, 2004, 2008 e 2012) e quatro títulos mundiais na Copa do Mundo da FIFA (1991, 1999, 2015 e 2019), enquanto a seleção masculina conquistou apenas uma medalha de bronze em Olimpíadas (1904) e sua melhor colocação em uma Copa do Mundo da FIFA foi um terceiro lugar, em 1930. Durante a Copa do Mundo da FIFA 
na França, em 2019, a atleta Megan Rapinoe, eleita a melhor atleta da competição e melhor jogadora do mundo no FIFA The Best 2019, ganhou visibilidade não apenas por suas habilidades com o futebol, mas também por ser uma voz ativa nas reivindicações por salários iguais (equal pay) no esporte, um discurso que ganha força e espaço quando a capitã da seleção americana e demais jogadoras se recusaram a ir à Casa Branca serem recebidas pelo presidente Donald Trump, e protagonizaram, enquanto campeãs, discursos públicos fervorosos em defesa das mulheres no esporte e da igualdade salarial. No mesmo evento, a brasileira Marta Silva, maior artilheira em Copas do Mundo da FIFA ${ }^{17}$ e seis vezes eleita a melhor jogadora do mundo pela FIFA (feito igualado por um homem apenas em 2019, o argentino Lionel Messi), se recusou a ser patrocinada por empresas que lhe pagassem menos do que pagavam para atletas homens. Um momento marcante na competição foi quando a atleta entrou em campo com uma chuteira preta, sem marca de nenhuma empresa, mas com o símbolo do movimento \#GoEqual, para o qual a jogadora apontou após fazer um dos gols da partida. Marta também é a maior artilheira da seleção brasileira, com 117 gols, contra apenas 95 gols de Pelé. Segundo artigo publicado na revista The Atlantic em $2015^{18}$, neste mesmo ano, o investimento anual que a seleção feminina de futebol brasileiro recebeu foi de $\mathrm{R} \$ 1,5$ milhões, enquanto o salário mensal do jogador Neymar naquele mesmo ano correspondia a R\$ 1 milhão. Em 2019, a jogadora de futebol mais bem paga do mundo, a norueguesa Ada Hegerberg, recebeu anualmente 400 mil euros, enquanto Messi recebeu 130 milhões de euros. Marta ganha receberá 340 mil euros no ano de 2019, enquanto Neymar receberá anualmente $€ 91$ milhões $^{19}$.

$17 \quad$ Marta marcou 17 gols, ultrapassando o alemão Miroslav Klose que marcou 16 gols em Copas do Mundo.

18 Revista The Atlantic, disponível em: https://www.theatlantic. com/entertainment/archive/2015/06/neymar-marta-world-cup-brazil/394856/?utm_source=SFTwitter, Acesso em: 18 outubro 2019.

19 Revista Época Negócios, disponível em: https://epocanegocios. globo.com/Mundo/noticia/2019/06/neymar-ganha-227-vezes-mais-que-ada-hegerberg-melhor-e-mais-bem-paga-jogadora-do-futebol-feminino.html Acesso em: 18 outubro 2019. 
$\mathrm{Na}$ indústria do entretenimento é possível acompanhar alguns eventos e dados para o debate sobre a igualdade salarial (equal pay) especialmente no cinema e nas produções das plataformas de streaming. Estudos realizados pelas agências shift7 e Creative Artists Agency - $\mathrm{CAA}^{20}$, responsáveis pelos contratos de grandes nomes de Hollywood, mostram que, apesar do baixo investimento em filmes protagonizados por mulheres, são estes os que mais arrecadam dinheiro com bilheterias. A exemplo, o filme Titanic (1998), segunda maior bilheteria da história do cinema, perdendo apenas para Avatar (2009), que também foi dirigido por James Cameron, figura o topo da lista das maiores bilheterias protagonizadas por mulheres. Kate Winslet protagonizou Titanic ao lado de Leonardo Di Caprio, e os cachês contratuais são altamente discrepantes. Titanic arrecadou US\$ 2,19 bilhões em bilheterias. Na época, Di Caprio assinou um contrato de US\$ 40 milhões, enquanto Winslet, vencedora do Oscar na ocasião, foi contratada por apenas US\$ 2 milhões para o mesmo filme. Vinte anos depois, Kate Winslet que também participou do filme Avatar de 2009, agenciada pela CAA, foi comemorada por fechar um contrato de US\$ 10 milhões para participar do segundo filme da franquia de Cameron. Um dos maiores cachês femininos da história do cinema, mas ainda assim, metade do que Di Caprio recebeu em 1998. Atualmente, as franquias de super-heróis da DC Comics e da Marvel figuram os maiores investimentos e as maiores bilheterias do cinema hollywoodiano. Mas se compararmos os investimentos dos filmes protagonizados por heroínas com os protagonizados por heróis, encontramos grandes diferenças numéricas e alguns avanços graduais. O filme Mulher-Maravilha (2017) da DC Comics foi o primeiro filme da empresa protagonizado por uma heroína, interpretada pela atriz Gal Gadot, e também foi o primeiro filme da DC Comics dirigido por uma mulher, Patty Jenkins. O contrato de Gadot foi fechado em US\$ 300 mil por filme em que a heroína aparecesse, totalizando US\$ 900

$20 \quad$ No site da Business Wire está disponível matéria sobre a pesquisa realizada pelas agências CAA e shift7, assim como o link para os dados estatísticos, disponível em: https://www.businesswire.com/news/ home/20181211005582/en/Female-Led-Films-Outperform-Budget-Levels-Research-Creative. Acesso em: 18 outubro 2019. 
mil sem incluir neste valor a participação nos lucros de produtos e bilheterias dos filmes Batman vs. Supeman: As Origens da Liga da Justiça (2016, arrecadou US\$ 873,6 milhões em bilheteria), Mulher-Maravilha (2017, arrecadou US\$ 821,8 milhões em bilheteria) e A Liga da Justiça (2017, arrecadou US\$ 657,9 milhões em bilheteria). Mulher-Maravilha está na história do cinema como o filme dirigido por uma mulher de maior arrecadação em bilheteria. Contudo, se compararmos os valores contratuais recebidos por Gadot pelos três filmes com o que o ator Henry Cavill recebeu também por três filmes da DC Comics, percebemos o abismo. $\mathrm{O}$ ator que, em seu primeiro filme vivendo um super-herói, Superman: O Homem de Aço (2013), era menos conhecido que Gal Gadot ao fechar contrato para viver Diana, apareceu também nos dois filmes da Liga da Justiça e recebeu por estes três filmes US\$ 14 milhões, sendo que o filme Superman teve uma arrecadação muito inferior ao filme Mulher-Maravilha: US\$ 668 milhões. Estes dados causaram muita discussão na época do lançamento do filme de Jenkins, que também assina a codireção dos demais filmes onde a personagem de Gadot aparece, e também foram base de especulações em matérias publicadas nos sites da Vanity Fair ${ }^{21}$ e The Daily $D^{2} t^{22}$, chamando atenção também para a diferença nos valores dos orçamentos dos filmes da DC Comis: enquanto $\mathrm{Mu}$ lher-Maravilha teve um custo de produção de US\$ 150 milhões, a maioria dos filmes da marca protagonizados por homens tem um custo médio de US\$ 200 milhões. Mulher-Maravilha foi a primeira grande produção cinematográfica protagonizada por uma super-heroína, e a primeira da DC Comics, que já visa novas produções cinematográficas com outras heroínas de seu universo dos quadrinhos.

O fenômeno a respeito dos investimentos em superproduções protagonizadas por mulheres e sobre o pagamento das atrizes causado pelo lançamento de Mulher-Maravilha teve im-

21

Revista Vanity Fair Disponível em: < https://www.vanityfair.com/ hollywood/2017/06/gal-gadot-wonder-woman-salary> Acesso em: 18 outubro 2019.

22 Revista Daily Dot Disponível em: < https://www.dailydot.com/parsec/wonder-woman-gal-gadot-pay-gap/> Acesso em: 18 outubro 2019. 
pacto nos estúdios rivais da DC Comics, a Marvel. A marca é responsável pelas mais milionárias produções do cinema nos últimos anos quando o assunto é tirar super-heróis dos quadrinhos e leva-los para as grandes telas do cinema. Mas a Marvel nunca havia investido em nenhuma produção protagonizada por uma heroína e as únicas personagens femininas com alguma relevância nos filmes da Marvel apareceram nas sequências de Os Vingadores (2012, 2015, 2018 e 2019) e Pantera Negra (2018): chamamos atenção para as personagens Viúva Negra (Scarlett Johansson), Nakia (Lupita Nyong'o), General Okoye (Danai Gurira) e Shuri (Letitia Wright). E foi justamente em 2019 que a Marvel lançou sua primeira produção protagonizada por uma heroína: Capitã Marvel. A produção teve o custo de apenas US\$ 152 milhões, o que é muito baixo se comparado com a maioria das produções da Marvel, que custam entre US\$ 200 e US\$ 400 milhões. Mesmo assim, a heroína vivida pela atriz Brie Larson se tornou a oitava maior arrecadação em bilheterias da Marvel e a décima maior bilheteria da história do cinema quando o assunto são filmes protagonizados por personagens femininas, com o total de US\$ 1,128 bilhão. Após o lançamento do filme da personagem mais poderosa dentre todos os heróis de sua franquia (Capitã Marvel), a Marvel já anunciou o lançamento do filme Viúva Negra para maio de 2020, onde Scarlett Johansson viverá a heroína Natasha Romanoff, com o orçamento de US\$ 110 milhões. Johansson foi a atriz mais bem paga em $2019^{23}$, recebendo US\$ 56 milhões pelo seu trabalho, enquanto o ator mais bem pago no mesmo ano, Dwayne "The Rock" Johnson, recebeu US\$ 89,4 milhões, seguido dos atores Chris Hemsworth (US\$ 76,4 milhões), Robert Downey Jr. (US\$ 66 milhões), Akshay Kumar (US\$ 65 milhões), Jackie Chan (US\$ 58 milhões), e Bradley Cooper e Adam Sandler (ambos com US\$ 57 milhões), segundo informações da Forbes ${ }^{24}$. O abismo salarial entre Johansson e "The Rock" ainda é imenso.

\footnotetext{
23 Revista Forbes Disponível em: < https://www.forbes.com/sites/maddieberg/2019/08/27/top-earning-actresses/\#2c0872295b79> Acesso em: 18 outubro 2019.

24 Ibid., Disponível em: <https://www.forbes.com/sites/maddieberg/2019/08/21/the-highest-paid-actors-2019-dwayne-johnson-bradley-
} 
Um outro caso que chamou muita atenção recentemente foi a luta da atriz Robin Wright por igualdade salarial (equal pay) em 2016. A atriz, que protagoniza a série House of Cards, do canal de streaming Netflix, pediu aos estúdios que seu salário fosse igualado ao do outro protagonista vivido por Kevin Spacey. Os estúdios concederam um aumento à atriz, mas não equiparou os salários dos dois atores, ainda que ambos, além de atuarem, fossem também produtores executivos da série e que tenham dirigido alguns episódios. Wright em entrevista à revista virtual Net-a-Porter ${ }^{25}$ conta sobre sua luta por equidade salarial e sobre como se sentiu enganada pela produtora da Netflix, pois ela pensava que estariam pagando a ela o mesmo salário pago a Kevin. Contudo, no mesmo ano de 2016, aparecem uma série de escândalos de abusos sexuais e acusações de estupro envolvendo Spacey, inclusive dentro da produção de House of Cards. O ator é afastado do programa e Wright ascende como a grande protagonista da série, passando a receber o maior salário da produção. Canais de notícias ao publicarem a luta de Wright na produção de House of Cards expõem três fragilidades da indústria do entretenimento: (1) a tolerância com abusos cometidos por homens em posições de poder; (2) o protagonismo menor concedido às personagens femininas e (3) a desigualdade salarial entre gêneros ${ }^{26}$.

Mas se a visibilidade para a injustiça que ocorre com a desigualdade salarial de gênero e o abismo salarial explodiu com o esporte e a indústria do entretenimento, o problema está longe de se limitar a estas esferas, e acontece em diversas áreas. No Brasil, segundo resultados do IBGE $^{27}$ divulgados em 2018, o número de mulheres com ensino superior é maior do que o de

-cooper-and-chris-hemsworth/\#1733e1b22b96> Acesso em: 18 outubro 2019.

25 Revista Net - A-Porter. A entrevista com Wright é posterior a divulgação dos escândalos envolvendo Kevin Spacey. Disponível em: < http://www. net-a-porter.com/am/magazine/402/18> Acesso em: 18 outubro 2019.

26 Revista Deadline. Disponível em: <https://deadline. com/2017/11/kevin-spacey-house-of-cards-on-set-complaint-netflix-producer-1202200810/> Acesso em: 18 outubro 2019.

27 Dados colhidos e divulgados pela Agência Brasil e IBGE. Disponível em: <https://www.ibge.gov.br/estatisticas/multidominio/genero/20163-es- 
homens (23,5\% contra 20.7\%). Mas em relação ao rendimento médio mensal de todos os trabalhos por sexo entre 2012 e 2016 as mulheres ganham em média apenas $75 \%$ do que os homens ganham. Este problema, de que mulheres realizam o mesmo trabalho que os homens embora não sejam remuneradas como eles, se mostra um mistério, que existe mas não é revelado. Como e por que isto acontece? Falta uma investigação maior do fenômeno, e faltam estatísticas mais detalhadas sobre este fenômeno silencioso, mas acreditamos que tanto para a explicação da desigualdade salarial de gênero (unequal gender pay) quanto para a explicação do abismo salarial (gender pay gap) seja importante avaliar atitudes psicológicas, culturais e morais, para que possamos ter uma compreensão mais ampla do problema, e para que assim sejamos capazes de combatê-lo. Propomos aqui 6 possíveis explicações, que acreditamos que podem ser dadas cumulativamente:

\section{A ganância masculina}

Os homens, em geral, estão mais propensos a buscar e aceitar cargos que sejam melhor remunerados, mesmo sabendo que não tem as qualificações necessárias para a função, enquanto as mulheres são mais reticentes a aceitar estas funções, e tendem a aceitar apenas os cargos e funções para as quais elas sabem que estão qualificadas e que exercerão bem e com competência, incluindo cargos de direção. A ganância masculina e sua avidez por dinheiro os torna cegos para a avaliação das suas próprias capacidades, por um lado; e por outro lado o que os move é justamente, prioritariamente, a possibilidade dos ganhos, deixando em segundo plano a preocupação com o bom exercício da função. Esta atitude, se prevalente nos homens, certamente elevaria a média salarial masculina, comparativamente a das mulheres, e influenciaria no abismo salarial (gender gap).

Do mesmo modo a ganância masculina pode ajudar na explicação sobre a desigualdade salarial de gênero (unequal pay).

tatisticas-de-genero-indicadores-sociais-das-mulheres-no-brasil.html? = \&$\mathrm{t}=$ o-que-e $>$ Acesso em: 18 outubro 2019. 
No setor público, por exemplo, onde teoricamente a desigualdade salarial de gênero não deveria existir, não há na realidade, infelizmente, dados estatísticos sobre como ela se apresenta, mas uma investigação poderia apresentar dados surpreendentes. Homens estão mais propensos a aceitar cargos de direção, mesmo quando não apresentam a necessária competência para isso; mulheres são muito mais críticas em relação a este procedimento. Mulheres estão mais interessadas do que os homens, em geral, em aceitar projetos e trabalhos voluntários, que embora sejam necessários para o bom andamento da coisa pública, não são assumidos por homens na mesma proporção, exatamente por não serem remunerados. Homens por outro lado tendem a assumir muito mais do que mulheres, projetos extras que trazem alguma remuneração extra, ainda que não tenham as necessárias competências e habilidades para tal. Em outras palavras mulheres estão muito mais dispostas do que os homens a fazerem pequenos sacrifícios pessoais, ou trabalharem mais, sem remuneração adicional, pelo bom andamento da coisa pública, enquanto os homens preocupam-se mais, em geral, com a obtenção de ganhos econômicos pessoais. Se este é o caso, a avidez masculina por projetos e funções que possibilitem ganhos pecuniários extras explicaria porque homens acabariam ganhando mais do que mulheres, mesmo no exercício do mesmo cargo.

\section{O apelo ao "direito natural" do pai de família}

A ideia de que homens casados e com filhos são "pais de família" que devem sustentar seus filhos e por isso são detentores de um direito especial, natural, é largamente difundida na sociedade. Isso tem reflexos no mundo do trabalho, já que aqueles responsáveis por contratações também são influenciados por esta ideia. Em sendo "pai de família" homens são considerados seres que tem prioridade na disputa de cargos e direito de ganhar mais do que outras pessoas que não estão na mesma condição. Ninguém nega que pais têm despesas adicionais com filhos, mas isto acontece também com as mães. Porque não é alegado que uma mulher é "mãe de família" para conceder a estas mães prioridade na disputa de cargos? Ao contrário, no 
caso das mulheres, o fato destas serem mães de família é visto como um fator desabonador no mundo do trabalho porque há sempre implicitamente a suspeita de que exatamente por ser mãe de família e ter responsabilidades familiares a mulher não vai dedicar-se ao seu trabalho como seria esperado. A cultura do "pai de família" acaba sendo discriminatória e certamente influencia no "gender gap" e provavelmente no "unequal pay". Sabe-se, porém que há um erro fundamental de princípio nesta visão. Muitos "pais de família" usam na realidade esta condição para conseguirem benefícios para si próprios, que não serão estendidos aos filhos. Sabe-se que nas políticas de concessão de renda mínima e redistribuição de renda um dos modos mais eficazes de fazer a distribuição é concedendo o benefício às mulheres mães de família, porque estas tendem em geral a usar o dinheiro em benefício da família, comprando alimentos, ao contrário dos homens que muitas vezes o utilizam em benefício pessoal, para compra de bebidas e até cigarros. A conclusão é que a ideologia do pai de família, embora difundida, é uma ideologia prejudicial e discriminatória no mundo do trabalho.

\section{O falso mito da maior produtividade masculina}

Há também o falso mito da maior produtividade masculina. A justificativa aqui para a desigualdade salarial é a de que os homens ganham mais porque são mais produtivos ou trabalham mais do que as mulheres. Um exemplo clássico desta justificativa é o do tênis, onde na maioria dos torneios as mulheres jogam no máximo três sets enquanto os homens jogam cinco sets, o que pode levar a diferenças expressivas no número de horas jogadas em uma partida. Entretanto, há vários exemplos de mulheres que jogaram várias horas seguidas em um torneio, alternando a participação em modalidades distintas. Por exemplo, a maior tenista brasileira de todos os tempos, Maria Ester Bueno, em 1967 jogou por mais de 10 horas seguidas em Wimbledon, o que lhe custou uma contusão que praticamente terminaria com sua carreira na década de 70. O mito de que os homens são mais produtivos do que as mulheres é tão aceito quanto facilmente desmentido. Muitas vezes a produção femi- 
nina supera a dos homens no mundo do trabalho, mesmo considerando o fato de que estas, muitas vezes, estão submetidas a dupla jornada de trabalho, o que não acontece com a grande maioria dos homens. Cabe também aqui a questão sobre o que é ser produtivo. É mais produtivo aquele que realiza uma tarefa rapidamente, mas deixando a desejar na qualidade ou quem finaliza a tarefa em um tempo um pouco maior, mas com maior perfeição? Se o segundo critério for utilizado no mundo do trabalho muito provavelmente o mito da maior produtividade masculina cairia definitivamente por terra.

\section{O apelo do pavão}

Os homens, em geral, são muito bons no talk the talk (palavreado) mas não tanto no walk the walk (nas ações). Os homens "pavoneiam" muito mais do que as mulheres, se autopromovem, dizem que fazem muito mais do que realmente fazem, enquanto as mulheres, em geral, são mais propícias a fazer o seu trabalho de forma eficiente, mas sem se vangloriar. Vivemos, entretanto, em uma sociedade de aparências, onde o "parecer" se torna mais valorizado do que o "ser", e assim sendo esta característica masculina de "pavonear" acaba sendo um dos fatores que contribui para sua melhor remuneração em relação as mulheres, não refletindo, porém, a situação real no mundo do trabalho em que as mulheres fazem o seu ofício com competência e eficácia, dia após dia, mas não "aparecem" tanto quanto os homens. Outro problema associado ao "pavonismo" é que o individualismo masculino é um empecilho ao trabalho coletivo, em equipe, que é essencial para o desenvolvimento de qualquer instituição ou empresa.

\section{Efeito Matilda}

O mundo do trabalho também é palco da invisibilidade do trabalho de muitas mulheres. E em muitos casos, acontece até a usurpação do trabalho realizado por algumas mulheres e o reconhecimento por este são atribuídos a homens. $\mathrm{Na}$ história há muitos casos de mulheres que realizaram trabalhos 
importantes em diversas áreas, como as artes e as ciências, e que nunca receberam o reconhecimento devido e, em alguns casos, tiveram o reconhecimento de seu trabalho atribuído a algum homem, de maridos à colegas de trabalho. Na ciência, casos do tipo recebem o nome de Efeito Matilda, em homenagem à sufragista Matilda Joslyn Gage, que escreveu um artigo em 1883 contra a ideia de que as mulheres seriam incapazes de genialidade e de realizar grandes descobertas e invenções científicas. $\mathrm{O}$ artigo se chama Woman as an Inventor ${ }^{28}$ aonde Matilde afirma "Nenhuma asserção em referência a mulheres é mais comum de que ela não possui nenhum gênio mecânico ou inventivo, mesmo com o censo dos Estados Unidos falhando em recensear as mulheres inventoras no País. Mas enquanto tais afirmações são feitas de modo desleixado ou ignorante, a tradição, a história e a experiência provam que ela possui estas faculdades no mais alto degrau. Embora a educação científica das mulheres tenha sido negligenciada, ainda assim, algumas das invenções mais importantes do mundo são devidas a elas". A partir disto a historiadora Margaret W. Rossiter, em 1993, deu o nome de Efeito Matilda ${ }^{29}$ para a tentativa da ciência de esconder as mulheres cientistas e até atribuir suas descobertas a homens cientistas ou não. Alguns casos famosos na ciência são os da médica italiana Trotula de Salerno, que viveu no século XI, que teve seus escritos sobre ginecologia atribuídos a homens após a sua morte; a polonesa Marie Curie, que só recebeu seu primeiro Prêmio Nobel, em 1903, graças aos esforços de Pierre Curie e Antonie Henri Becquerel para que a cientista fosse reconhecida e dividisse com eles o prêmio pelas investigações sobre a radiação, sendo também a primeira mulher a receber

GAGE, Matilda Joslyn. "Woman as an Inventor". The North American Review, v. 136, n. 318 (May, 1883): p. 478-489. No texto lê-se: "No assertion in reference to woman is more common than that she possesses no inventive or mechanical genius, even the United States census failing to enumerate her among the inventors of the country. But, while such statements are carelessly or ignorantly made, tradition, history, and experience alike prove her possession of these faculties in the highest degree. Although woman's scientific education has been grossly neglected, yet some of the most important inventions of the world are due to her."

29 ROSSITER, Margaret W. "The Matthew/ Matlida effect in Science". Social Studies of Science, v.23 (1993): p.325-341. 
o prêmio e, em 1911 recebeu o prêmio novamente pela descoberta dos elementos rádio e plutônio; a inglesa Rosalind Elsie Franklin, que descobriu a estrutura do DNA, mas quem recebeu o reconhecimento e o Nobel em 1962 pela descoberta foram seus colegas Francis Crick e James Dewey; a britânica Jocelyn Bell Burnell, que descobriu e analisou as pulsões de rádio, mas quem recebeu o reconhecimento e o Nobel em 1972 pela descoberta foi seu orientador Anthony Hewish; e a austríaca Lise Meitner, que descobriu a fissão nuclear, mas teve a descoberta atribuída pelos nazistas a Otto Hahn, que recebeu o Nobel pela descoberta. E além da ciência, temos casos como da pintora norte-americana Margaret Keane, cujo marido Walter Keane assinava suas obras e a mantinha sob ameaça, e da também estadunidense Elizabeth Magie ou Lizzie Magie, que inventou um jogo de tabuleiro que chamou de Landlord's Game em 1903, mas que três décadas depois a invenção passou a ser creditada a Charles Darrow e ficou famosa com o nome de Monopoly. Muito além da ciência, em diversos setores é possível encontrar a tentativa de invisibilizar o trabalho das mulheres e também a apropriação do trabalho e também do reconhecimento deste por homens. A credibilidade e o reconhecimento dados a muitos homens por feitos realizados por mulheres alimentam alguns mitos e fatos que constroem algumas das explicações dadas anteriormente, como a ganância masculina, o mito da produtividade masculina, o apelo do pavão e até mesmo o princípio de Fannie Hurst. Podemos dizer que, de fato, atrás de "grandes" homens da história, existem grandes mulheres, como hidden figures ou figuras ocultadas pela figura masculina, e responsáveis pela "grandiosidade" atribuída a estes homens.

\section{O Princípio Fannie Hurst}

Fannie Hurst, uma escritora americana nascida ao final do século XIX escreveu uma frase que se imortalizou: "Uma mulher tem de ser duas vezes melhor que um homem para conseguir chegar até a metade de onde ele chega". Isto acontece no plano salarial também. Parece que as mulheres têm de ser duas vezes melhor do que os homens para ganhar três quartos do 
que eles ganham, como podemos verificar pelos fenômenos do unequal gender pay, ou seja, desigualdade salarial de gênero, e do gender pay gap, ou seja, o abismo salarial entre os gêneros. Fannie Hurst foi extremamente feliz com sua frase, que pensamos tratar-se de uma das melhores caracterizações do machismo que ocorre no mundo do trabalho, e na vida em geral. As mulheres têm de trabalhar e se esforçar muito mais do que os homens para serem reconhecidas e recompensadas financeiramente como os homens são. A igualdade salarial entre homens e mulheres não existe. No mundo do trabalho, como na vida, a mulher é vista no mundo machista como a intrusa, aquela que conquistou seu espaço sem ser convidada, lutando por ele, lutando por um espaço tradicionalmente destinado para aquele a quem este espaço pertencia de direito, ou seja, o homem. O mundo do trabalho é um mundo masculino, e neste mundo nós somos, tomando emprestado a expressão de Simone de Beauvoir, o outro, ou melhor, as outras.

\section{Conclusão}

Simone de Beauvoir no segundo sexo ${ }^{30}$ pergunta: porque a mulher é o outro? Ela afirma que a biologia não é suficiente para fornecer uma resposta a esta pergunta já que se trata aqui de saber o que a humanidade fez da fêmea humana. Simone diz que o mundo sempre pertenceu aos machos ${ }^{31}$. Simone diz que podemos compreender que o homem tenha tido vontade de dominar a mulher, mas resta a pergunta: que privilégio lhe permitiu satisfazer esta vontade? Para Beauvoir a chave do mistério está no fato de que não é gerando a vida, e sim arriscando a vida que o homem se ergue acima de todo animal ${ }^{32}$. Essa é a razão pela qual, na humanidade, a superioridade não é outorgada ao sexo que gera, e sim ao que mata. Segundo Simone, a fêmea, mais do que o macho, é presa da espécie. ${ }^{33}$ Voltaremos a Simone

$30 \quad$ BEAUVOIR, Simone. O Segundo Sexo. São Paulo, Difusão Européia do Livro, 1970. v.1, Fatos e Mitos. p.57.

$\begin{array}{ll}31 & \text { Ibid.,p.81 } \\ 32 & \text { Ibid., p.84 } \\ 33 & \text { Ibid.,p.85 }\end{array}$


de Beauvoir mais adiante, mas neste momento precisamos analisar a conjuntura política, econômica, social e cultural mundial.

O que acontece no mundo e no Brasil nos dias de hoje? Culturalmente estamos as portas da barbárie, com as redes sociais, sem nenhuma regulação, sendo o canal que dá vazão a toda espécie de ofensas aqueles que pensam diferente do ofensor. Nas mesmas redes sociais alguns se arvoram o direito de criar e divulgar como se verdadeiro fossem, fatos que não existem, divulgando mentiras e afrontando a realidade e o bom senso. Politicamente um fenômeno semelhante se repete, com empresas que fabricam boatos e mentiras sendo contratadas por quantias milionárias por aqueles interessados em manipular o povo e destruir a democracia. Chefes de estado sem nenhum compromisso com a coisa pública e com a ciência negam a existência de fenômenos que são criados pela mão humana na forma de ganância e que ameaçam a vida no planeta, como o aquecimento global. Em termos sociais e econômicos a desigualdade nunca foi tão grande no mundo. Segundo dados da Oxfam $^{34}$ em 2018 chegamos ao ponto em que os 26 mais ricos bilionários do mundo possuem a mesma riqueza que os 3.8 bilhões de pessoas que constituem os $50 \%$ mais pobres do mundo. Ao mesmo tempo, adverte a Oxfam que os homens possuem $50 \%$ a mais da riqueza do mundo que as mulheres e controlam $86 \%$ das corporações. O trabalho de "cuidar", não pago, que é realizado pelas mulheres no mundo, é estimado em 10 trilhões de dólares.

A igualdade entre homens e mulheres nunca existiu, sabemos disto. Nos anos 90 pensamos, talvez, que caminhávamos nesta direção, mas o século XXI mostrou que a luta pelos direitos das mulheres é constante, e que pode sim haver retrocessos, de modo que devemos estar sempre vigilantes. A luta que é preciso lutar hoje não é apenas a luta contra a barbárie, pela civilização, mas é também a luta pela sobrevivência da espécie humana e pela sobrevivência da vida no planeta. O capitalismo selvagem que vivemos é um modo de produção masculino. A

34 Oxfam International disponível em https://www.oxfam.org/en/ even-it/5-shocking-facts-about-extreme-global-inequality-and-how-even-it-davos Acesso em: 18 outubro 2019. 
cultura da morte, com a apologia das armas, é essencialmente masculina. O crime social, embora as estatísticas mostrem um aumento da participação feminina neste, continua sendo essencialmente praticado por homens. As guerras são na sua imensa maioria provocada pelos machos de nossa espécie. Podemos ousar dizer, pedindo já perdão a Freud, que se existe uma tensão constante entre Eros e Tanathos (a pulsão de vida e a pulsão de morte) entre os humanos, as mulheres representam muito bem a Eros e os homens representam muito bem a Tanathos.

Um dos grandes problemas do século XXI, porém, é que o mundo, o planeta terra, não pode mais suportar a vitória do ethos masculino, a vitória do ethos de Tanathos. A vitória de Tanathos pode significar, na prática, não só o fim da civilização como conhecemos, mas também, literalmente o fim do mundo e o fim da vida no planeta Terra.

E aqui, para concluir, voltamos a Beauvoir, como prometido. Se a mulher é "presa da espécie" como ela alertou, chamamos atenção para o fato de que há algo de muito positivo nisto, especialmente em um tempo como o de agora, em que a espécie humana está ameaçada pela loucura de machos pseudo humanos que são literalmente os atuais donos do mundo, ou que pensam sê-lo. Somos nós, presas da espécie, que ao pensar muito mais na espécie do que nos interesses individualistas somos capazes de superar a ganância e o egoísmo, estes soldados da morte, e criar um caminho de resistência à destruição, na afirmação de uma ética altruísta, solidária e que tenha como objetivo a manutenção e valorização não só da vida humana, mas da vida como um todo no planeta. A luta pela igualdade salarial entre homens e mulheres não é apenas uma luta por igualdade salarial, ela é parte de uma luta muito maior do que essa, uma luta por Justiça, por respeito, pela vitória da civilização, pela vitória da vida, pela vitória de Eros. 


\section{Referências:}

BEAUVOIR, Simone O Segundo Sexo (São Paulo, Difusão Européia do Livro, 1970) v.1 Fatos e Mitos

GAGE, Matilda Joslyn "Woman as an Inventor" The North American Review,v. 136, n. 318 (May, 1883)

ROSSITER, Margaret W "The Matthew/ Matilda effect in Science" Social Studies of Science v.23 (1993)

Agência Brasil e IBGE. Disponível em: <https://www.ibge.gov.br/ estatisticas/multidominio/genero/20163-estatisticas-de-genero-indicadores-sociais-das-mulheres-no-brasil.html $=\& \mathrm{t}=\mathrm{o}$-que-e $>$

IBGE, censo demográfico disponível em https://www.ibge.gov.br/ apps/snig/v1/?loc $=0 \&$ cat $=-1,1,2,-2,3,4,13,48,128 \&$ ind $=4699$

Oxfam international disponível em https://www.oxfam.org/en/even-it/5-shocking-facts-about-extreme-global-inequality-and-how-even-it-davos

Revista Business Wire disponível em: https://www.businesswire.com/news/home/20181211005582/en/

Female-Led-Films-Outperform-Budget-Levels-Research-Creative.

Revista Daily Dot Disponível em: < https://www.dailydot.com/ parsec/wonder-woman-gal-gadot-pay-gap/>

Revista Deadline Disponível em: <https://deadline.com/2017/11/ kevin-spacey-house-of-cards-on-set-complaint-netflix-producer-1202200810/>

Revista Época Negócios, disponível em: https://epocanegocios.globo. com/Mundo/noticia/2019/06/neymar-ganha-227-vezes-mais-que-ada-hegerberg-melhor-e-mais-bem-paga-jogadora-do-futebol-feminino.html

Revista Forbes Disponível em: <https://www.forbes.com/sites/ maddieberg/2019/08/27/top-earning-actresses/\#2c0872295b79

Revista Net - A- Porter. Disponível em: <http://www.net-a-porter. com/am/magazine/402/18>

Revista The Atlantic, disponível em: https://www. theatlantic.com/entertainment/archive/2015/06/ neymar-marta-world-cup-brazil/394856/?utm_source=SFTwitter

Revista Vanity Fair disponível em: < https://www.vanityfair.com/ hollywood/2017/06/gal-gadot-wonder-woman-salary>

The Global Gender Gap Report 2018 http://www3.weforum.org/docs/ WEF_GGGR_2018.pdf World Economic Forum 